Thorax (1950), 5, 333.

\title{
PULMONARY HISTOPLASMOSIS
}

\author{
BY \\ P. G. ARBLASTER \\ From University College Hospital, London
}

(RECEIVED FOR PUBLICATION JULY 19, 1950)

Human infection by the fungus Histoplasma capsulatum produces two syndromes which are similar to those following infection by Coccidioides immitis.

The first syndrome to be recognized was a generalized affection of the reticuloendothelial system, described by Darling (1906, 1908, and 1909) and fully detailed by DeMonbreun (1934). The second syndrome is characterized by pulmonary calcification associated with a positive intradermal response to histoplasmin. It was recognized by Palmer (1945) and more fully described by High, Zwerling, and Furcolow (1947). This is the first report in England of an example of the latter type. The case is of special interest because the 10-year period of observation is longer than in any previously reported case and the presenting symptom is unique.

In 1938 Gass, Gauld, Harrison, Stewart, and Williams drew attention to the fact that in Tennessee many people had radiological evidence of pulmonary calcification but no local response to tuberculin injection. Crimm and Short (1939) postulated that the absence of local response was due to the development of a state of anergy. This theory was disputed by Aronson, Saylor, and Parr (1942), who demonstrated that such patients, following injection of B.C.G., will in the normal way develop sensitivity to tuberculin. Palmer (1945), investigating similar cases, noted the frequent occurrence of a local reaction to the intradermal injection of histoplasmin, which is a filtrate of a culture in the mycelial phase of Histoplasma capsulatum. In the Mississippi valley area High and others (1947) found that 62 out of 15,980 children whose ages ranged from 1 to 18 years old had pulmonary calcification. Of these $93.5 \%$ were positive reactors to histoplasmin alone, and a further $3.3 \%$ positive reactors to histoplasmin and tuberculin. In the same year Furcolow, Mantz, and Lewis obtained similar results from an investigation of 16,000 children in Kansas City.

From this and other similar evidence it has been concluded that in certain geographical areas a significant correlation exists between the presence of intrathoracic calcification and skin sensitivity to histoplasmin. The demonstration of pulmonary calcification associated with both skin sensitivity to histoplasmin and insensitivity to tuberculin does not in itself justify the conclusion that the pulmonary lesions are due to histoplasmosis. However, Furcolow (1949) has considerably clarified this problem by the isolation of Histoplasma capsulatum from two such cases.

\section{CASE REPORT}

In January, 1949, a man aged 36 years was admitted to University College Hospital. He had had a large haemoptysis and was in a state of shock. 
FIG. 1.-Radiograph (kindly lent by Dr. P. A. Galpin) of chest, August 28, 1940.

FIG. 2.-Radiograph of chest, December 17, 1949.

FIG. 3.-The same, showing detail of the "dot and ring" calcification at the left base.

FIG. 3
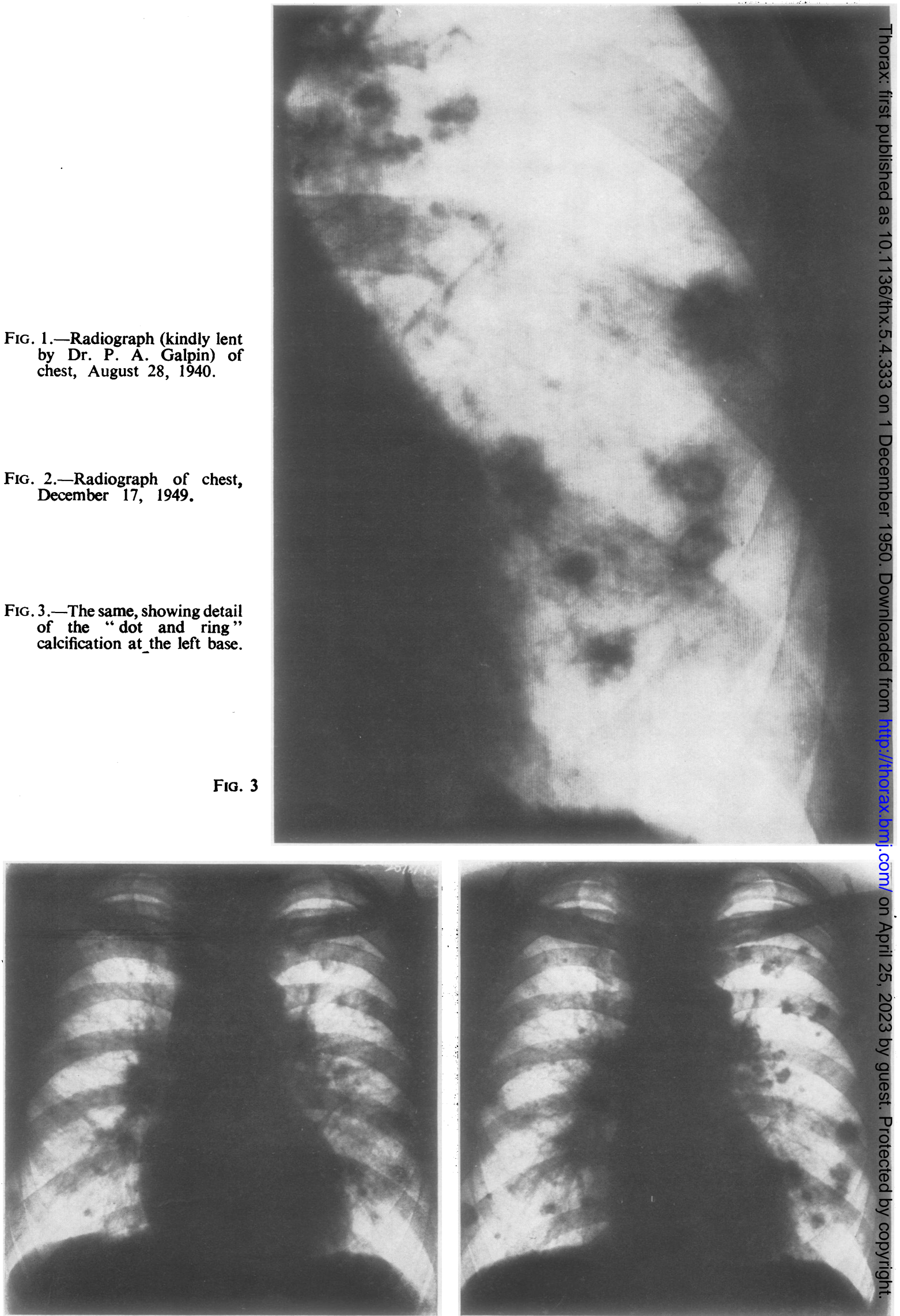

Fig. 1

FIG. 2 
Most of the patient's earlier life had been spent in England, but for a period of six years before 1937 he had lived in Canada employed as an agricultural labourer and had divided his stay between Montreal and the nearby Great Lakes. In 1938 he joined the British Army and in that year developed the first symptoms of his present illness. Following a bout of coughing he expectorated a small volume of fresh blood. On three subsequent days there were further haemoptyses which prompted him to seek medical attention and he was admitted to hospital.

He was thought to have pulmonary tuberculosis and was discharged from the Army to the care of his borough tuberculosis officer. After this he worked as a flat-roof repairer and remained well until 1945 when during two weeks he had several haemoptyses. These were either provoked or made worse by exercise. Following a short rest at home he returned to work. Except for the onset of early dyspnoea on exertion in the winter of 1948 he was well until January, 1949, when he once again coughed blood. The loss was slight, but two days later it suddenly became considerable and he was admitted to University College Hospital.

One week after admission and following blood transfusion the patient's condition had improved considerably. He was not cyanosed and no petechiae or ecchymoses were found in the skin or mucous membranes. Abnormal physical signs were few and were localized to the chest. For the first week there were multiple sonorous rhonchi heard over most areas but more easily on the right side. A systolic murmur, louder on inspiration, was most distinctly audible just below the angle of the right scapula but could be detected over most of the posterior surface of the right chest. Other signs were a soft, blowing systolic murmur in the region of the maximum cardiac impulse and, finally, a small, firm, unfixed lymphatic gland in the left axilla.

A chest radiograph (Fig. 2) revealed numerous nodular lung lesions, many of which were calcified and ranged from 0.25 to $1.5 \mathrm{~cm}$. in diameter. The mediastinal abnormalities were gross, and some of the lung lesions had an unusual appearance which has been described by Furcolow and others (1947) as " halo calcification" ; this is illustrated in Fig. 3. Fig. 1 is a reproduction of a radiograph taken in 1940. The progressive increase of calcium deposition between 1940 and 1949 was obvious, but it was difficult to decide whether any new lesions had developed.

The likely diagnosis seemed to be pulmonary tuberculosis. The sputum was examined on nine occasions, but no acid-fast bacilli were found. Six cultures for tubercle bacilli on Löwenstein-Jensen and Dorset egg media were also negative. Intradermal old tuberculin, $0.1 \mathrm{ml}$. of dilution $1: 1,000$, produced a positive skin response. The erythrocyte sedimentation rate was $35 \mathrm{~mm}$. in the first hour (Westergren $200 \mathrm{~mm}$. tube). The total and differential white blood cell count was normal ; and one week after transfusion the haemoglobin level was found to be $84 \%$ of normal (Haldane).

Bronchoscopy on two occasions showed the tracheal mucous membrane to be a little oedematous; it bled easily and the whole structure felt rigid. The main bronchi and segmental bronchial orifices seemed normal.

The finding of a normal oxygen saturation in blood from the right brachial artery made the possibility of pulmonary arteriovenous anastomoses seem unlikely.

The radiographs of limb and skull bones were normal. It was suggested that the chest radiographs had appearances not unlike those seen following infection by the trematode Paragonimus westermani. Sputum examinations for ova were negative. By exclusion the most likely aetiological agent was thought to be a fungus. No local response was obtained to the injection of coccidioidin diluted $1: 10$, but a severe local reaction followed the injection on August 5, 1949, of standard histoplasmin $0.1 \mathrm{ml}$. at a dilution of $1: 10$. After three days, at the site of injection there was a disc-like area of erythema and oedema $11 \mathrm{~mm}$. in diameter and an enlarged tender lymphatic gland in the axilla of the same side. Further tests, using injections of $0.1 \mathrm{ml}$. of $1: 1,000$ 
dilution of known active standard histoplasmin, were made four and five months later. On both occasions there was a local response amounting to an area of erythema and oedema $10 \mathrm{~mm}$. in diameter 48 hours after the injection : $10 \mathrm{~mm}$. of oedema is regarded as a positive response by Edwards, Lewis, and Palmer (1948).

Two estimations of the complement-fixing antibodies known to be produced sometimes during the course of histoplasmosis were made.* Both sera fixed complement to a titre of $1: 10$ with histoplasmin antigen. This according to present experience is probably not significant. Collodion particles on which histoplasmin had been absorbed were not agglutinated by two serum specimens from the patient. This test, though perhaps less sensitive, gives results parallel with the complement-fixation test.

Attempted culture of the fungus from four sputum and two faecal specimens on penicillin and streptomycin screened blood agar plates was unsuccessful. Sternal marrow culture, one of the most sensitive diagnostic procedures, was found to be negative. A smear of the sternal marrow stained for Histoplasma capsulatum by the periodic acid Schiff method with suitable counterstain was also negative. These results one might reasonably have adduced from the prolonged nature of the patient's illness.

On the basis of the data recorded, it was considered that the patient was infected by the fungus Histoplasma capsulatum.

\section{Criteria of Diagnosis}

The Specificity of the Histoplasmin Test.-Emmons, Olson, and Eldridge (1945) showed in experimental histoplasmosis in animals that non-specific skin responses were obtained by injections of blastomycin, coccidioidin, and haplosporangin, these being extracts of Blastomyces dermatitidis, Coccidioides immitis, and Haplosporangium parvum. More recently Christie and Peterson (1945), in a study of 39 animals infected with Histoplasma capsulatum, found cross specificity of local skin reaction with coccidioidin in only one animal. Despite these early reports Howell (1947) has shown that, in cases of histoplasmosis, blastomycin does not give a nonspecific reaction if used in correct strength. Smith, Saito, Beard, Rosenberger, and Whiting (1949) have reported similar findings with coccidioidin. I have been unable to find a recorded case of human infection by Haplosporangium parvum: Emmons and Ashburn (1942) have reported infection in rodents of San Carlos, Arizona. It is perhaps important that they found minute granulomatous pulmonary lesions.

Howell (1947) also showed that histoplasmin preparations require initial assay as they are not of equal potency. However, the usual suitable strength to produce a specific skin response has been shown by Edwards and others (1948) to be $0.1 \mathrm{ml}$. of $1: 1,000$ dilution of the standard preparation. Prior, Cole, and Torbet (1949) have demonstrated its specificity in experimental histoplasmosis in dogs. Except in a few patients moribund from the disease, all human cases of histoplasmosis proved by cultural methods have had a positive histoplasmin response. It would thus seem reasonable in the case under discussion, in the absence of local sensitivity to coccidioidin, to attach considerable significance to the repeated finding of histoplasmin sensitivity.

The Complement-Fixation Test.-A complement-fixation test was described in detail by Campbell and Saslaw in 1949. It was shown to be reliable in following the progress of acute generalized histoplasmosis and occasionally of use in the

*These estimations were made by Miss C. C. Campbell, of the Army Medical Centre in Washington. 
diagnosis of the syndrome under discussion. In two series of volunteer controls a titre such as is usually regarded as diagnostic of histoplasmosis was found in small percentages: 5.9 and $7.7 \%$. However, when complement is fixed in a titre at, or higher than, $1: 80$ serum dilution, the test is specific.

Furcolow (1949) has recorded examples of histoplasmosis, proved by culture of the fungus, in which at times a normal titre was found; and Bunnell and Furcolow (1948) described a case of histoplasmosis that did not develop a significant complement-fixation titre until the third year of the disease. Thus the absence of a significant titre in two serum specimens in no way invalidates the diagnosis of histoplasmosis, and only points to the desirability for further estimations.

The test has provided a useful index of antibody response following histoplasmin injection. Campbell and Saslaw have demonstrated such antibodies for as long as 20 days following histoplasmin tests. Further, it is known that repeated histoplasmin injections do not cause a prolonged state of local skin sensitivity to the antigen (Riddell, 1950). These observations are apposite to the possible objection that the initial skin test on this patient, using a highly concentrated histoplasmin solution, produced a prolonged state of sensitivity and thus gave false positive reactions to the subsequent correct strength histoplasmin injections. It will be noted that there was between the first and second tests an interval of four months; and this makes a false positive response extremely unlikely.

The Chest Radiograph Appearances.-The chest radiograph appearances of histoplasmosis were described clearly by Furcolow and others (1947), by Sontag and Allen (1947), and by High and others (1947). The association of disseminated nodular pulmonary lesions with gross hilar adenopathy has been found in the majority of proved histoplasmosis cases. The mediastinal changes in the case described are typical, both in character and in the considerable degree of glandular enlargement. The multiple foci, which were mostly discrete, in places coalesced to form the "raspberry-like" opacities noted by Furcolow and others (1947).

The lung lesions illustrated were more extensive than is usual in histoplasmosis, but their individual components were characteristic. The calcified lesions varied in size from 0.25 to $1.5 \mathrm{~cm}$. in diameter. Some foci had a peripheral zone of calcification which produced the "halo" or "dot and ring" appearances illustrated in Fig. 3. These two features, gross hilar adenopathy and halo lung calcification, were findings highly suggestive of a diagnosis of histoplasmosis. Both are useful in the important problem of radiographic differentiation between histoplasmosis and pulmonary tuberculosis.

These considerations lead to the diagnosis of histoplasmosis in our case. The basis of this conclusion was, first, the positive skin reaction to correct strength histoplasmin, and, secondly, the typical pulmonary radiographs. Sensitivity to old tuberculin was not regarded as a bar to diagnosis.

\section{Histoplasmosis in England and Canada}

Indications of the presence of histoplasmosis in Canada were first provided by Guy, Roy, Poupart, and Panisset in February, 1949.

In England a fatal case of generalized histoplasmosis was reported by Derry, Card, Wilson, and Duncan (1942). Their patient had been in the Army and had 
travelled outside the British Isles. Duncan (1945), in a survey of fungus diseases in England, mentions two cases. The first was Derry's case and the second a patient with skin lesions from which a positive culture had been obtained. The latter was fully reported by Duncan (1947). The diagnosis of a case of histoplasmosis in England is thus a curiosity. Surveys for examples of skin sensitivity to histoplasmin have been made by McWeeney, Crowe, Dunlevy, and Magan (1946) in Dublin, and by McCracken (1948) in South Wales with negative results. Evidence of an opposite nature, namely that lung calcification in English children is always associated with tuberculin sensitivity, has been compiled by Thompson (1948).

No animal histoplasmin surveys have been reported in England. In America, histoplasmosis has been described in dogs by Prior, Cole, and Torbet (1949), in rats and skunks by Emmons, Morlan, and Hill (1949), and in cattle by Furcolow and Ruhe (1949). Emmons and others demonstrated rodent infection in Georgia, an area where the disease is not endemic in man. Olson, Bell, and Emmons (1947) failed to find a significant relationship between animal and human histoplasmosis. Thus, even if animal infection is later demonstrated in this country, it may not be a potent source of danger.

\section{DiscUSSION}

The date of infection in this case may be calculated from the time when calcification first became apparent in the chest radiographs. There is evidence provided by Sontag and Allen (1947) that such deposition takes two years to become radiographically visible. It has only been possible to obtain written reports of radiographs taken in 1938: in these there is no mention of calcified opacities. The 1940 radiograph reveals calcified lesions, and thus infection probably occurred during or before 1938. This evidence accords with the observations of Guy and others (1949), and suggests that infection took place while the patient was living in Canada between 1931 and 1937.

There are two unusual features of this case. First, the occurrence of haemoptysis, a unique though not surprising symptom which Smith (1943) has described in the closely analogous coccidioidomycosis. Secondly, at the back of the right chest a systolic murmur was heard: of this phenomenon no adequate explanation is offered.

\section{SUMMARY}

A case of pulmonary histoplasmosis is described. Infection probably took place in Canada. The case is unusual because the presenting symptom was haemoptysis and the period of observation was 10 years.

I wish to acknowledge with thanks the considerable help of Dr. Howard Nicholson, under whose care the patient was admitted to University College Hospital. I also wish to thank Dr. S. Cochrane Shanks for the radiographs and Mr. A. Bligh for the illustrations; Dr. R. W. Riddell, of the London School of Hygiene and Tropical Medicine, for the supply of histoplasmin, and Dr. Joan Stokes for the bacteriological investigations.

\section{REFERENCES}

Aronson, J. D., Saylor, R. M., and Parr, E. I. (1942). Arch. Path., 34, 31.

Bunnell, I. L., and Furcolow, M. L. (1948). P.ıbl. Hlth Rep., Wash., 63, 299.

Campbell, C. C., and Saslaw, S. (1949). Ibid., 64, 551.

Christie, A., and Peterson, J. C. (1945). Amer. J. publ. Hlth, 35, 1131. 
Crimm, P. D., and Short, D. M. (1939). Ann. intern. med., 13, 61; Amer. Rev. Tuberc., 39, 64.

Darling, S. T. (1906). J. Amer. med. Ass., 46, 1283. (1908). Arch. intern. Med., 2, 107. (1909). J. exp. Med., 11, 515.

DeMonbreun, W. A. (1934). Amer. J. trop. Med., 14, 93.

Derry, D. C. L., Card, W. I., Wilson, R., and Duncan, J. T. (1942). Lancet, 1, 224.

Duncan, J. T. (1945). Brit. med. J., $2,715$. (1947). Trans. R. Soc. trop. Med. Hyg., 40, 364.

Edwards, L. B., Lewis, I., and Palmer, C. E. (1948). Publ. Hlth Rep., Wash., 63, 1569.

Emmons, C. W., and Ashburn, L. L. (1942). Ibid., 57, 1715. Morlan, H. B., and Hill, E. L. (1949). Ibid., 64, 1423

- Olson, B. J., and Eldridge, W. W. (1945). Ibid., 60, 1383.

Furcolow, M. L. (1949). Ibid., 64, 1363. Mantz, H. L., and Lewis, I. (1947). Ibid., 62, 1711. and Ruhe, J. S. (1949). Amer. J. Publ. Hlth, 39, 719

Gass, R. S., Gauld, R. L., Harrison, E. F., Stewart, H. C., and Williams, W. C. (1938). Amer. Rev. Tuberc., 38, 441 .

Guy, R., Roy, O., Poupart, G., and Panisset, M. (1949). Canad. J. publ. Hlth, 40, 68.

High, R. H., Zwerling, H. B., and Furcolow, M. L. (1947). Publ. Hith Rep., Wash., $62,20$.

Howell, A. (1947). Ibid., 62, 631.

McCracken, B. H. (1948). Thorax, 3, 45.

McWeeney, E. J., Crowe, M., Dunlevy, M., and Magan, M. (1946). J. med. Ass., Eire, $19,162$.

Olson, B. J., Bell, J. A., and Emmons, C. W. (1947). Amer. J. publ. Hlth, 37, 441.

Palmer, C. E. (1945). Publ. Hlth Rep., Wash., 60, 513.

Prior, J. A., Cole, C. R., and Torbet, V. (1949). Ibid., 64, 1562.

Riddell, R. W. (1950). Personal communication.

Smith, C. E. (1943). Med. Clin. N. Amer., 27, 790.

- Saito, M. T., Beard, R. R., Rosenberger, H. G., and Whiting, E. G. (1949). Amer. J. publ. Hlth, 39, 722.

Sontag, L. W., and Allen, J. E. (1947). J. Pediat., 30, 657.

Thompson, B. C. (1948). Thorax, 3, 43. 